\title{
XXIII. On the phosphorograph of a solar spectrum, and on the lines in its infra-red region
}

\section{John William Draper M.D.}

To cite this article: John William Draper M.D. (1881) XXIII. On the phosphorograph of a solar spectrum, and on the lines in its infra-red region, Philosophical Magazine Series 5, 11:67, 157-169, DOI: $10.1080 / 14786448108626993$

To link to this article: http://dx.doi.org/10.1080/14786448108626993

册 Published online: 24 Aug 2010.

Submit your article to this journal $₫$

Џ Article views: 6

Q View related articles $\sqsubset$ 


\title{
LONDON, EDINBURGH, AND DUBLIN
}

\section{PHILOSOPHICAL MAGAZINE}

\author{
AND \\ JOURNAL OF SCIENCE. \\ [FIFTH SERIES.] \\ $M A R C H 1881$.
}

XXIII. On the Phosphorograph of a Solar Spectrum, and on the Lines in its Infra-red Region. By JOHN WILLIAM Draper, M.D., Professor of Chemistry in the University of New York*

T PROPOSE in this communication to consider (1) the 1 peculiarities of a phosphorograph of the solar spectrum as compared with a photograph of the same object; (2) the antagonization of effect of rays of higher by those of lower refrangibility.

There is a striking resemblance between a photograph of that spectrum taken on iodide of silver and a phosphorograph taken on luminous paint and other phosphorescent preparations. There are also differences.

\section{Description of the Photographic Spectrum.}

In 1842 I obtained some very fine impressions of the first kind (on iodide of silver), and described them in the Philosophical Magazine, November 1842, and again in February 1847. One of these was made the subject of an elaborate examination by Sir J. Herschel. His description and explanatory views of it may be found in that journal, February 1843 .

From these it appears that such a photograph, taken in presence of a weak extraneous light, may be considered as pre-

* Read before the American Academy of Arts and Sciences, and communicated by the Author.

Plil. Mag. S. 5. Vol. 11. No. 67. March 1881. N 
senting three regions:-1. A middle one, extending from the boundary of the blue and green to a little beyond the violet; in this region the argentic iodide is blackened. 2. Below this, and extending from the boundary of the blue and green to the inferior theoretical limit of the prismatic spectrum, is a region strongly marked, in which the action of the daylight has been altogether arrested or removed, the daylight and the sunlight having apparently counterbalanced and checked each other. 3. A similar protected region occurs beyond the violet; this, however, is very much shorter than the preceding. The sketch annexed to Herschel's paper represents these facts as well as they can be by an uncoloured drawing.

\section{Description of the Phosphorographic Spectrum.}

In a phosphorograph on luminous paint the same general effects appear. If the impression of the spectrum be taken in the absence of extraneous light, there is a shining region corresponding to the blackened region of the photograph. But if, previously or simultaneously, extraneous light be permitted to be present, new effects appear. The shining region of the phosphorograph has annexed to it, in the direction of the less-refrangible spaces and extending toward the theoretical limit of the spectrum, a region of blackness in striking contrast to the surrounding luminous surface. This blackness, however, is broken at a distance below the red by a luminous rectangle of considerable width. This occupies the space, and indeed arises from the coalescence, of the bands $a, \beta, \gamma$, discovered by me in 1842. It may be separated into its constituent bands, which are very discernible when registered on gelatine as presently described. And since this is not so easily done with the upper lines of the spectrum, we may infer that these are very much broader than the Fraunhofer lines, a result strengthened by the fact that these dark intervals can be more easily recognized by the thermopile than those lines. The blackness is then resumed. It extends to a short distance; and there the phosphorographic impression comes to an end.

This shining rectangle has long been known to students of phosphorescence; but its interesting origin has not until now been explained.

But more, just beyond the region of the violet, the same kind of action occurs-a dark space, which, however, is of very much less extent than that beyond the red.

The photograph and the phosphorograph thus present many points of similarity. But though there are these striking points of resemblance, there are also striking differences. 
In a spectrum four or five centimetres long, though the photograph may be crossed by hundreds of Fraunhofer lines, not one is to be seen in the phosphorograph, except those just referred to. The spectrum must be dispersed much more before they can be discerned.

\section{Of the Propagation of Phosphorescence from Particle to Particle.}

The explanation of this disappearance of the Fraunhofer lines is obvious. A phosphorescing particle may emit light enough to cause others in its neighbourhood to shine; and each of these in its turn may excite others; and so the luminosity may spread. In a former memoir I examined this in the case of chlorophane, and concluded that in that substance such a communication does not take place; but now, using more sensitive preparations, as follows, I have established in a satisfactory manner that it does.

The test plate referred to in the next parapraph was thus made. A piece of glass was smoked on one side in a flame, until it became quite opaque. When cool a few letters or words were written on it. Some photographic varnish was poured on it and drained. This, drying quickly, gave a black surface which could be handled without injury.

A phosphorographic tablet was made to shine by exposure to the sky. It was then carried into a dark room, and the test plate laid upon it. On the test plate another non-shining phosphorographic tablet was laid, and kept in that position a few minutes; then, on lifting this from the test plate, the letters were plainly visible, especially if it were laid on a piece of hot metal. So the light radiating from the first tablet through the letters of the test could produce phosphorescence in the second tablet, through glass more than a millimetre thick.

This lateral illumination is therefore sufficient to destroy the impression that is left by the fixed lines, unless indeed their breadth be sufficiently exaggerated and as short an interval as possible permitted between the moment of insolation and that of observation.

It has been remarked that a photograph taken from a phosphorograph is never sharp. It looks as if it were taken out of focus, and this even though it may be a copy by contact. The light has spread from particle to particle. Under such circumstances, sharpness is impossible, because the phosphorograph itself is not sharp. 
For this reason also, the bright rectangle in a phosphorograph of the solar spectrum, arising from the coalescence of the infra-red lines $\alpha, \beta, \gamma$, is never sharp on its edges. It seems as if it were fading away on either side. It is also broader than would correspond to the actual position and width of those lines ; and, particularly, it is somewhat rounded at its corners.

If we could obtain a thermograph of the solar spectrum, it would correspond very closely to the phosphorograph. The particles heated would radiate their heat to adjwcent ones. Nothing like sharpness of definition could be obtained, except in very brief exposures before the effect had had time to spread.

\section{Examination of Phosphorescent Tablets by Gelatine Photography.}

The examination of a phosphorescent surface can be made now in a much more satisfactory manner than formerly. The light we have to deal with, being variable, declines from the moment of excitation to the moment of observation; and, though the phosphori now prepared are much more sensitive and persistent than those formerly made, they must still be looked upon as ephemeral. To examine them properly, the eye must have been a long time in darkness to acquire full sensitiveness.

It was recommended by Dufay to place a bandage over one eye, that its sensitiveness might not be disturbed, whilst the other, being left naked, could be used in making the necessary preparations. But this on trial will be found, though occasionally useful, on the whole an uncomfortalule and unsatisfactory method.

The exceedingly sensitive gelatine-plates now obtainable remove these difficulties. The light emitted by blue phosphori, such as luminous paint, consists largely of rays between $H$ and $G$; and these are rays which act at a maximum on the gelatine preparation. So if a gelatine plate be laid on a shining blue phosphorus it is powerfully affected, and any mark or image that may have been impressed on the phosphorus will on development in any of the usual ways be found on the gelatine. The gelatine has no need to wait after the manner of the eye. It sees the phosphorus instantly. It is impressed from the very first moment; and whilst the eye is accommodating itself and so losing the best of the effect, the gelatine is gathering every ray and losing nothing. Moreover the effect upon it is cumulative. The eye is 
affected by the intensity of the emitted light, the gelatine by its quantity. Each moment adds to the effect of the preceding. The gelatine absorbs all the light that the phosphorus emits from the moment of excitation, or by suitable arrangement any fractional part thereof:. It has another most important advantage. The phosphorus is yielding an ephemeral result, and is momentarily hastening to extinction; so that for a comparison of such a result with others of a like kind the memory must be trusted to. But the gelatine seizes it at any predetermined instant, and keeps it for ever. These permanent representations can at any future time be deliberately compared with one another.

To these still another advantage may be added. Very frequently an impression is much more perceptible on a gelatine copy than it is on the phosphorus from which that copy was taken. This arises from the fact that the eye is made less sensitive by the light emitted from surrounding phosphorescent parts, and cannot perceive a sombre point or line amongst them. This is a physiological effect. But a gelatine copy in no respect dazzles or enfeebles the eye. For this reason, for instance, we may not be able in a phosphorograph to resolve visually the infra-red bright rectangle into its constituent lines, but we recognize them instantly in the gelatine.

I have made use of sensitive gelatine plates ever since their quality of being affected by phosphorescent light was announced by Messrs. Warnecke and Darwin. The more sensitive of the plates receives a full effect by an exposure of less than one minute.

But all kinds of phosphori will not thus affect a photographic tablet : there inust be a sympathy between the phosphorescent and the photographic surfaces. Thus a phosphorus emitting a yellow light will not affect a photographic preparation which requires blue or indigo rays. This principle I detected many years ago. In my memoir on phosphorescence (Phil. Mag., February 1851), it will be seen that the green light emitted by chlorophane could not change the most sensitive photographic preparation at that time known (the daguerreotype plate); and hence I was obliged, in measuring the light it emits, to resort to Bouguer's optical method. The result would have turned out differently had the light to be measured been more refrangible, blue or indigo or violet.

A photographic surface agrees with the retina in this, that it has limits of sensitiveness. The eye is insensible to rays of much lower refrangibility than $A$ and much higher than 
H. Gelatine cannot perceive rays lower than $\mathrm{F}$; but it is affected by others far higher than H. There is therefore a range for each, having its limits and also its place or point of maximum sensitiveness. But some substances, such as the iodide and bromoiodide of silver, under special mothods of treatment, are either affected positively or negatively throughout the entire range of the spectrum.

In experiments for obtaining quantitative results, it should be borne in mind that there is generally a loss of effect. Between the moment of insolation and that of perception, either by the eye or by gelatine, emitted light escapes. The moment of maximum emission is the moment of completed insolation ; and from this the light rapidly declines. It is necessary, therefore, to make that interval between the two moments as short as possible.

\section{Of the Eatinction of Phosphorescence by Red Light.}

I turn now to an examination of those parts of the phosphorographic spectrum from which the light has been removed. They are from the line $F$ to the end of the infra-red space, and again for a short distance above the violet. The effect resembles the protecting action in the same region of a photograph.

Now, if similar effects are to be attributed to similar causes, we should expect to find in the photograph and phosphorograph the manifestation of a common action.

Several different explanations of the facts have been offered. Herschel suggested that the photograph might be interpreted on the optical principle of the colours of thin films. Very recently Captain Abney has attributed the appearance of the lower space to oxidation. But this can scarcely be the case in all instances. Mr. Claudet showed, in a very interesting paper on the action of red light, that a daguerreotype plate can be used again and again by the aid of a red glass, and that the sensitive film undergoes no chemical change (Phil. Mag., February 1848).

It was known to the earliest experimenters on the subject that if the temperature of a phosphorescent surface be raised, the liberation of its light is hastened, and it more quickly relapses into the dark condition. In the memoir to which I have previously referred (Phil. Mag., February 1851), I examined minutely into this effect of heat, and determined the conditions which regulate it. And since, on the old view of the constitution of the solar spectrum, the heat was supposed 
to increase toward the red ray, and when flint-glass or rock salt-prisms are employed to give its maximum far beyond that ray, it was supposed that this heat expelled the light, and consequently in all those parts of the phosphorus on which it fell the surface became dark through the expulsion or exhaustion of the light.

I speak of this as " the old view," because, as I have elsewhere shown, the curve supposed to represent heat, light, and actinism, so called, have in reality nothing to do with those principles. They are merely dispersion-curves having relation to the optical action of the prism and to the character of the surface on which the ray falls. (Phil. Mag., August 1872, December 1872.)

But this heat explanation of the phosphorescent facts cannot be applied to the photographic. Nothing in the way of hastened or secondary radiation seems to take place in that case.

In phosphorescence the facts observed in the production of this blackness are these. If a shining phosphorescent surface be caused suddenly to receive a solar spectrum, it will instantly become brighter in the region of the less-refrangible rays, as will plainly appear on the spectrum being for a moment extinguished by shutting off the light that comes into the dark room to form it. If the light be re-admitted again and again, the like increase of brilliancy may again and again be observed, but in a declining way. Presently, however, the region that has thus emitted its light begins to turn darker than the surrounding luminous parts. If now we no longer admit any spectrum-light, but watch the phosphorescent surface as its luminosity slowly declines, the region that has thus shot forth its radiation becomes darker and darker, and at a certain time quite black. The surrounding parts in the course of some hours slowly overtake it, emitting the same quantity of light that had previously been expelled from it ; and eventually all becomes dark.

Now, apparently, all this is in accordance with the hypothesis of the expulsion of the light by heat. There are, however, certain other facts which throw doubt on the correctness of that explanation.

On that hypothesis, the darkening ought to begin at the place of maximum heat-that is, when flint-glass apparatus is used, below the red ray; and from this it should become less and less intense in the more refrangible direction. But in many experiments; carefully made, I have found that the maximum of blackness has its place of origin above the line $\mathrm{D}$, and, indeed, where the orange and green rays touch each 
other. Not unfrequently, in certain experiments the exact conditions of which I do not know and cannot always reproduce, the darkening begins at the upper confines of the green, and slowly passes down to beyond the red extremity; that is to say, its propagation is in the opposite direction to that which it ought to show on the heat hypothesis.

Still more, as has been stated, there is a dark space above the violet. Now it is commonly held that in this region there is little or no heat. If so, what is it that has expelled or destroyed the light.

The experiments above referred to I made with the recently introduced luminous paint. It presented the facts under their simplest form. But I have also tried many other samples, for which I am indebted to the courtesy of Professor Barker of Philadelphia. Among them I may mention as being very well known the specimens made by Dubose, enclosed in flat glass tubes, contained in a mahogany case, and designed for illustrating the different-coloured phosphorescent lights emitted. They are to be found in most physical cabinets. These, however, do not show the facts in so clear a manner. On receiving the impress of a solar spectrum they present patches of light and shade irregularly distributed. Though in a general way they confirm the statements made above, they do not do it sharply or satisfactorily.

Dubosc's specimens to which I have had access are enumerated as follows:-1. Calcium viulet; 2. Calcium blue; 3. Calcium green; 4. Strontium green; 5. Strontium yellow ; 6. Calcium orange. Restricting my observation to the space beyond the red (which, as has been said, presents a bright rectangle in the darkness, about as far below the red as the red is below the yellow) I found that this rectangle is not given by 1 and 2 ; in 3 it is doubtful; in 4 it is quite visible; and in 5 and 6 strikingly so.

Is the blackening then due to heat? That it occurs beyond the violet (that is, beyond the lines H) seems to render such an opinion doubtful; for it is commonly thought that the effect of heat is not recognizable there. And in the phosphorogenic spectroscope I have used, the optical train (prism, lenses, \&c.) is of glass, which must of course exercise a special selective heat-absorption ; but the traces of this in the phosphorograph I could never detect.

In the diffraction-spectrum, I had attempted nearly forty years ago to ascertain the distribution of heat (Phil. Mag., March 1857), but could not succeed with the experiment in a completely satisfactory manner, so small is the effect. I exposed a tablet of luminous paint to such a diffraction-spec- 
truin formed by a reflecting grating having 17,296 lines to the inch, and was not a little surprised to see that from the blue to the red end of the spectrum there is an energetic extinction of the light, and darkness is produced. I repeated this with other gratings, and under varied circumstances, and always found the same effect.

Now, considering the exceedingly small amount of heat available in this case, and considering the intensity of the effect, is there not herein an indication that we must attribute this result to some other than a calorific canse?

1 endeavoured to obtain better information on this point by using the rays of the moon, which, as is well known, are very deficient in heating-power. Many years ago I had obtained some phosphorographs of that object. With the more sensitive preparations now acessible, and with a telescope of 11 inches aperture and 150 inches focus, there was no difficulty in procuring specimens about 1.4 inch in diameter. These represented the lunar surface satisfactorily. At half-moon an exposure of three or four seconds was sufficient to give a fair proof. But, on insolating a phosphorescent tablet, and causing the converging moon-rays to pass through the red glass which I commonly use as an extinguisher, no effect was produced by the red moonlight on the shining surface.

I repeated this experiment, using a lens 5 inches in diameter and 7 inches focus, so arranged that the moon's image could be kept stationary on the phosphorescent tablet. That image was about $\frac{1}{5}$ inch in diameter. Then, insolating the tablet, the moon-rays, after passing through a red glass, were caused to fall upon it. The exposure continued ten minutes; but no effect was produced on the shining surface. The lunar image was so brilliant that when the red glass was removed, and a non-shining phosphorescent surface was exposed to it, a bright image could be produced in a single second.

But in order to remove the effect of the more refrangible rays by the less, the latter must not only have the proper wave-length but also the proper amplitude of vibration. This principle applies both to photographic and phosphorographic experiments. In my memoir on the negative or protecting rays of the sun (Phil. Mag., February 1847) it is said, "Before a perfect neutralization of action between two rays ensues, those rays must be adjusted in intensity to each other." It requires a powerful yellow ray to antagonize a feeble day-light.

It is owing to the difference in amplitude of vibration that the heat of radiation seems so much more effective than the heat of conduction. A temperature answering to that of the 
boiling-point of mercury must be applied to a phosphorescent tablet for quite a considerable time before all the light is extinguished. But the red end of the spectrum and that even of the diffraction-spectrum, in which the heat can with difficulty be detected by the most sensitive thermometer, accomplishes it very quickly.

\section{On the Infra-red Lines or Bands in the Sun's Spectrum.}

At a distance about as far below the red as the red is below the yellow in the solar spectrum, I found in 1842, in photographs taken on iodide of silver (Daguerre's preparation), three great lines or bands, with doubtful indications of a fourth still further off. I designated them as $\alpha, \beta, \gamma$, and published an engraving of them in the Philosophical Magazine for May 1843.

In 1846, MM. Foucault and Fizeau having repeated the experiment thus originally made by me, presented a communication to the French Academy of Sciences. They had observed the antagonizing action above referred to, and had seen the infra-spectral lines $a, \beta, \gamma$. They had taken the precaution to deposit with the Academy a sealed envelope, containing an account of their discovery, not knowing that it had been made and published long previously in America.

Sir J. Herschel had made some investigations on the distribution of heat in the spectrum, using paper blackened on one side and moistened with alcohol on the other. He obtained a series of spots or patches, commencing above the yellow and extending beyond the red. Some writers on this subjecthave considered that these observations imply a discovery of the lines $a, \beta, \gamma$. They forget, however, that Herschel did not use a slit, but the image of the Sun, an image which was more than a quarter of an inch in diameter. Under such circumstances, it was impossible that these or any other of the fixed lines could be seen.

I have many times repeated this experiment, but could not obtain the same result, and therefore attributed my want of success to unskilfulness. More recently Lord Rayleigh (Phil. Mag., November 1877), having experimented in the same direction, seems to be disposed to attribute these images to a misleading action of the prism employed. Whatever their cause may be, it is clear that they have nothing to do with the fixed lines $a, \beta, \gamma$ now under consideration.

In these experiments, and also in others made about the same time on the distribution of heat in the spectrum, I attempted to form a diffraction-spectrum without the use of any dioptric 
media, endeavouring to get rid of all the disturbances which arise through the absorptive action of glass by using as the grating a polished surface of steel on which lines had been ruled with a diamond, and employing a concave mirror instead of an achromatic lens; and though my results were imperfect and incomplete, I saw enough to convince me that it is absolutely necessary to employ a spectrum that has been formed by reflection alone. (Phil. Mag., March 1857, p. 155.)

In 1871, M. Lamanski succeeded in detecting these lines or bands by the aid of a thermomultiplier. He was not adequately informed on what had already been done in the matter. in America ; for he says that, "with the exception of Foucault and Fizeau in their well-known experiments on the interference of heat, no one as yet has made reference to these lines." Nearly thirty years before the date of this memoir I had published an engraving of them (Phil. Mag., May 1843).

After I had discovered these three lines, I intended to use the grating for the exploration of that region, since it extends it far more than the prism can do-but on making the attempt was discouraged by the difficulty of getting rid of the more refrangible lines belonging to the second spectrum. I had hoped to eliminate these by passing the ray on its approach to the slit through a solution of the bichromate of potash. But the bichromate in long exposures permits a sufficiency of the more refrangible rays to pass, to produce a marked photographic effect; and hence 1 feared that any experiments supposed to prove the existence of lines in the infra-red would be open to the criticism that they in reality belonged to the more refrangible region of the spectrum of the second order, and that a satisfactory examination of the case would exclude the use of the grating and compel that of the prism. With the prism I could not obtain clear evidence of the existence of more than three lines, or perhaps groups, and doubtful indications of a fourth. If in these examinations we go as far as wave-length 10,750, the limit of Captain Abney's map, we nearly reach the line $\mathrm{H}^{2}$ of the third spectrum. This would include all the innumerable lines of spectrum 2, and even many. of those of spectrum 3 . In such a vast multitude of lines, how would it be possible to identify those that properly belonged to the first, and exclude those of the second and third spectra? Besides, do we not encounter the objection that this is altogether beyond tho theoretical limit of the prismatic spectrum? 
This brings us to Captain Abney's recent researches, which, by the aid of the grating, carry the investigation referred to the prismatic spectrum as far below the red as the red is below the yellow. They are not to be regarded as an extension of exploration in the infra-red region (for they really do not carry us beyond my own observations in 1843), but as securing the resolution of these lines or bands into their constituent elements. I had never regarded them as really single lines; the breadth or massiveness of their photographs too plainly suggests that they are composed of many associated ones. The principle of decreasing refrangibility with increasing wave-length incapacitates the prism from separating them; but the grating (which spreads them out according to their wave-length) reveals at once their composite character.

In Captain Abney's map, after leaving the red line A, we find three groups :- (1) ranging from about 8150 to 8350 ; (2) from 8930 to 9300 ; (3) from 9350 to 9800 . These, admitting that the lines of the subsequent grating-spectra have been excluded, are then the resolution of $a, \beta, \gamma$.

I suppose that care has been taken to make sure of that, either by absorbent media or by a subsidiary prism. If the grating had been ruled in such a manner as to extinguish the second spectrum, inconveniences would arise from the characteristics thereby impressed on the first.

In the phosphorographic spectrum on luminous paint, this vast multitude of lines is blended into a mass which probably can never be completely resolved into its elements, on account of the propagation of phosphorescence from particle to particle. I have resolved it into two or three constituent groups, and frequently have seen indications of its capability of resolution into lines, in the serrated aspect of its lateral edges.

I believe that luminous paint enables us to approach very nearly, if not completely, to the theoretical limit of the prismatic spectrum.

The history of these interesting infra-red lines is briefly this. They were discovered by me in 1842 , and an engraving and description of them given in the Philosophical Magazine.' They were next seen by Foucault and Fizeau in 1846, and a description of them presented to the French Academy of Sciences. They were again detected by Lamanski with the thermopile in 1871. Their resolution into a great number of finer lines was accomplished by Abney, who gave a Bakerian lecture describing them before the Royal Society in 1880 . Finally they have been redetected by me 
in the shining rectangle, just above the theoretical limit of the prismatic spectrum, given by many phosphorescent substances.

University of New York,

Dec. $1,1880$.

XXIV. On the Determination of Chemical Affinity in terms of Electromotive Force.-Part IIII.* By C. R. AlDER WRIGHT, D.Sc. (Lond.), Lecturer on Chemistry and Physics in St. Mary's Hospital Medical School†.

On the Absolute Values of the Ohn and of the Mechanical Equivalent of Heat, and on the Nature of Polarization and Electrolysis, and the amount of work done when the latter occurs.

55. QINCE the publication of Parts I. and II. of these D researches, it has been obligingly pointed out by Mr. L. B. Fletcher, of Baltimore (Phil. Mag. [5] x. p. 436), that, by a slip, it is stated in $\S 35$ that the values of the B.A. unit of resistance deducible from the 1867 experiments of Joule and from those detailed in Part II., are from 1.5 to 2.0 per cent. above one earth-quadrant per second, instead of that amount below this theoretical value, it being assumed that the mean water-friction value of Joule (41.555 megalergs, \$34) is correct; and Mr. Fletcher also states that the first results of an experimental redetermination of the absolute value of the ohm, on which he is now engaged, are similar in character. Besides the valuations of Lorenz and Kohlrausch, briefly referred to in Part $I$. as illustrations of the want of absolute certainty as to the true value of the B.A. unit, two other sets of observations on this point have been made within the last two or three years-one by Prof. H. A. Rowland (Silliman's Journal [3] Xv. pp. 281, 325, and 430,1878), and the other by H. F. Weber (Phil. Mag. [5] v. pp. 30, 127, and 189, 1878). By making observations of the value of the current induced in one coil by the establishment of a measured current in another one, Rowland obtained values of the resistance of the former such that, by comparison with four copies of the B.A. unit (or a multiple thereof), the following numbers were obtained as the resistance of the latter:-

* Part I., Proceedings of the Physical Society, 1880, vol. iii. p. 213; also Phil. Mag. April 1880. Part II., Proc. Phys. Soc. 1880, vol. iii. p. 246; also Phil. Mag. May 1880.

$\uparrow$ Communicated by the Physical Society. 